\title{
Gender, Technology, and Libraries
}

Information technology (IT) is vitally important to many organizations, including libraries. Yet a review of employment statistics and a citation analysis show that men make up the majority of the IT workforce, in libraries and in the broader workforce. Research from sociology, psychology, and women's studies highlights the organizational and social issues that inhibit women. Understanding why women are less evident in library IT positions will help inform measures to remedy the gender disparity.

T echnology not only produces goods and services, it also influences society and culture and affects our ability to work and communicate. As the computer encroaches more deeply into both workplaces and homes, encouraging participation in the development and use of technology by all segments of society is important. Libraries, in particular, need to provide services and products that both appeal to and are accessible by a broad range of clientele. For libraries, information technology (IT) has become vitally important to the operation of the organization. Yet fewer women are active in IT than men. A complex series of social and cultural biases inhibits women from participating in technology both in the library and in the larger workforce. The inclusion of more women in technology would alter the development and design of products and services as well as change the dynamic of the workplace. Understanding why women reject IT as it is currently practiced is necessary to understanding how to make technology more inviting for women.

\section{Occupational data}

Studies and statistics from the broader IT fields highlight discrepancies between the compensation, managerial level, and occupational roles of men and women. ${ }^{1}$ Among the numbers are those showing that computer and information science fields include only 519,700 females and slightly more than 1,360,000 males in $2003 .^{2}$ In the same occupational fields, men earned a median of $\$ 74,000$ while women earn $\$ 63,000 .^{3}$ Similarly, the Association of Research Libraries (ARL) statistics from 2004 to 2008 show that men were more often employed as the heads of computer systems departments within libraries. Computer systems department heads also earned higher salaries than the heads of other library departments. With the exception of 2004-5, female computer department heads were paid less than their male counterparts, despite the fact that they had more years of experience. In the 2007-8 report, men and women
Table 1. Library computer systems department heads

\begin{tabular}{llccc}
\hline Year & Gender & $\begin{array}{c}\text { Depart- } \\
\text { ment } \\
\text { Heads }\end{array}$ & Salary & $\begin{array}{c}\text { Years in } \\
\text { Field }\end{array}$ \\
\hline $2004-5$ & Women & 32 & 76,764 & 18.9 \\
& Men & 60 & 76,060 & 16.9 \\
$2005-6$ & Women & 32 & 78,767 & 19.4 \\
& Men & 52 & 79,680 & 18.4 \\
$2006-7$ & Women & 26 & 81,435 & 18.2 \\
& Men & 52 & 82,409 & 17.6 \\
$2007-8$ & Women & 27 & 87,107 & 18.8 \\
& Men & 51 & 87,136 & 18.8 \\
\hline
\end{tabular}

had the same number of years of experience, though women's salaries lagged slightly behind those of the men, as shown in table $1 .^{4}$

The availability of statistics for the heads of library technology departments belies the difficulty in counting the number of technology positions in libraries, or the broader workplace, and compiling statistics by gender. In a recent study of the job satisfaction of academic library IT workers, Lim comments on the complexities in identifying survey participants, "as a directory of library IT workers does not exist." ${ }^{15}$

Thus, to augment the statistical data for department heads, a citation analysis was used to identify those persons involved enough in library technology to write about it. Presumably, authors of articles appearing in technology-oriented journals would have interests and expertise in technology regardless of their position titles or locations within the organization. Technology-related articles can and do appear in a wide variety of library journals. Journals with a focus on technology were selected to avoid the dilemma of subjectively categorizing individual articles as technical or nontechnical.

The journals selected provide a cross-section of association, commercial, electronic, and print publications. Information Technology and Libraries is the journal of the Library Information Technology Association division of the American Library Association (ALA). The Journal of Information Science and Technology (JASISET) is an official publication of the American Society for Information Science and Technology. The not-for-profit Corporation for National Research Initiatives publishes D-Lib Magazine, an

Melissa Lamont (mlamont@ rohan.sdsu.edu) is Digital Collections Librarian, San Diego State University. 
electronic publication on digital library research and development. All three are peer-reviewed. Computers in Libraries, published by Information Today, includes case studies and how-we-did-it articles and is not peer-reviewed. Emerald publishes the peer-reviewed journal Library Hi Tech.

The author assembled statistics for the years 2006 and 2007. For the survey, regular columns, editors' sections, reviews, short notices, and association communications were not counted. Each authored article was counted. No attempt was made to include or discount an article based upon the topic. The gender of the authors was determined by notes within the journal, authors' websites, other Internet sites, or by communication with the authors. As the statistics in table 2 demonstrate, men publish in these journals at a far higher rate than women, with the exception of Computers in Libraries. Women make up 35 percent of the authors while men make up 65 percent.

JASISET, arguably the most technical and theoretical journal in the analysis, and the journal with the most academic authorship, illustrates the highest disparity. Alternatively, the publication Computers in Libraries contains more articles authored by women. This publication solicits articles on the application of technology-practical and less formal articles to share successes and ideas.

It may be argued that female librarians simply publish less than male librarians. Two additional publications, The Journal of Academic Librarianship, published by Elsevier, and College and Research Libraries (CERL), published by the Association of College and Research Libraries, were analyzed for comparison. Table 3 illustrates the data for the comparison journals alone, with women making up 62 percent of the authors. Female authors outnumbered male authors in the comparison journals, but women account for approximately 80 percent of U.S. librarians and are therefore publishing at a lower rate than men. ${ }^{6}$

In the interest of comparison, the author also analyzed the journal Children and Libraries, the journal of the Association for Library Service to Children, a division of ALA. In 2006 and 2007, only four male authors were represented in Children and Libraries. They appeared as authors a total of eleven times. All of the remaining fifty authors are female. Women made up 82 percent of the total authors while men made up 18 percent.

These statistics are similar to a study conducted by Hakanson and published in 2005. She analyzed articles in selected journals from the years 1980 to 2000 and found that male authors slightly outnumbered female authors, and further that articles authored by men were more likely to be referenced than those by women. ${ }^{7}$ The data gathered here are similar: 41 percent of the total authors in both technology and comparison journals are women, and 59 percent are men. Male authors also are more likely to be the lead author on articles with multiple authors. Again JASISET shows the greatest disparity. Computers in Libraries includes more female lead authors, as shown in table 4 . In the comparison journals, women are more often the lead author, as shown in table 5 .

Both Hakanson's data and the small statistical sample reported here demonstrate that although women hold most library positions, they do not publish a comparable amount. Technology journals show the most disparity between the numbers of male and female authors.

Together, the citation and occupational statistics illustrate the higher visibility men have in IT. Fewer women are evident in IT as department heads, employees, academics, or authors.

Table 2. Gender of authors in technology journals, 2006-7

\begin{tabular}{lrrrrr}
\hline Publication & Articles & \multicolumn{2}{c}{ Female Authors } & \multicolumn{2}{c}{ Male Authors } \\
\hline & & \multicolumn{1}{c}{$\#$} & \multicolumn{1}{c}{$\%$} & \multicolumn{1}{c}{$\#$} & \multicolumn{1}{c}{$\%$} \\
Computers in Libraries & 57 & 51 & 61.4 & 32 & 38.6 \\
D-Lib Magazine & 92 & 83 & 38.6 & 132 & 61.4 \\
Information Technology & 43 & 28 & 33 & 57 & 67 \\
\& Libraries & & & & & \\
JASIS\&T & 354 & 244 & 30.3 & 560 & 69.7 \\
Library Hi-Tech & 91 & 63 & 41.2 & 90 & 58.8 \\
Totals & $\mathbf{6 3 7}$ & $\mathbf{4 6 9}$ & $\mathbf{3 5}$ & $\mathbf{8 7 1}$ & $\mathbf{6 5}$ \\
\hline
\end{tabular}

Table 3. Gender of authors in comparison journals, 2006-7

\begin{tabular}{lccccc}
\hline Publication & Articles & \multicolumn{2}{c}{ Female Authors } & \multicolumn{2}{c}{ Male Authors } \\
\hline & & $\#$ & $\%$ & $\#$ & $\%$ \\
$\begin{array}{l}\text { College \& Research } \\
\text { Libraries }\end{array}$ & 66 & 81 & 63 & 48 & 37 \\
$\begin{array}{l}\text { Journal of Academic } \\
\text { Librarianship }\end{array}$ & 128 & 140 & 61 & 89 & 39 \\
Totals & 194 & 221 & 62 & 137 & 38 \\
\hline
\end{tabular}




\section{Discussion}

In the broader workplace, not just libraries, men hold the majority of IT positions. The importance of including women in IT is not just a matter of equal opportunity. According to Rasmussen and Hapnes, women will bring different concerns and outlooks to IT. Further, the products and services produced by a diverse and integrated workforce will appeal to a broader market. Including more women in the IT workplace will also alter the organizational environment. Their ideas and interests will bring new perspectives to development discussions and likely lead to new or different systems. ${ }^{8}$ Understanding why relatively few women enter IT fields will help inform measures to alter the current, male-dominated dynamic. By reviewing the research in sociology, psychology, and women's studies, the factors inhibiting women from participation in IT can start to be understood. The dissuasive factors are a complex and intertwined combination of organizational culture, occupational segregation, and subtle discrimination.

\section{Abilities and perceptions}

Technology is pervasive throughout the library, and nearly all librarians develop basic technical skills as a condition of employment. Librarians may develop more advanced computing skills to address a lack of technical support, to develop new services, or for professional or personal interest. Correspondingly, technologists have

Table 4. Gender of lead authors in technology journals, 2006-7

\begin{tabular}{lccc}
\hline Publication & Articles & Female First & Male First \\
\hline Computers in Libraries & 20 & 12 & 8 \\
D-Lib Magazine & 50 & 22 & 28 \\
Information Technology & 17 & 7 & 10 \\
\& Libraries & & & \\
JASIS\&T & 140 & 32 & 108 \\
Library Hi-Tech & 42 & 19 & 23 \\
Totals & 269 & 92 & 177 \\
\hline
\end{tabular}

Table 5. Gender of lead authors in comparison journals, 2006-7

\begin{tabular}{lccc}
\hline Publication & Articles & Female First & Male First \\
\hline $\begin{array}{l}\text { College and Research } \\
\text { Libraries }\end{array}$ & 39 & 29 & 10 \\
$\begin{array}{l}\text { Journal of Academic } \\
\text { Librarianship }\end{array}$ & 61 & 36 & 25 \\
Totals & 100 & 65 & 35 \\
\hline
\end{tabular}

absorbed library concepts such as description and classification. Yet knowledge and ability are valued and evaluated within the social context of the organization, according to Scott-Dixon. The location of an occupation within the organization will influence the perception of the ability and skill required to succeed in that position. ${ }^{9}$ Although the work of librarians and technologists may be similar or interdependent, the occupations are valued differently. Scott-Dixon's research addresses the problem of "designating which work is technical enough to merit consideration as IT work."10 Technologically proficient librarians or staff working outside of the IT department will not be considered part of the library's IT staff, yet they may be performing at a technological level equal to that of the regular IT staff. Scott-Dixon states, "Assumptions about IT work incorporate assumptions about who performs this work, and that work performed in traditionally nonwhite, non-male jobs is often viewed as less technical, regardless of the technological objects that are employed in the process."11 The number of women participating in IT may be higher than the statistics represent; nevertheless, women are still less directly employed in IT. Any contributions they make to IT will be devalued as a consequence of their positions within the library organization.

Position and department titles also influence the perceived value of the work. To make traditional library tasks appear modern and relevant, long-established library functions have been renamed. Cataloging has become metadata, catalog control has become system administration, and librarianship has become information science. The old chestnut that information science is library science for boys has an element of truth. In 2006, the average annual starting salary for librarians who categorize their positions as information science was $\$ 48,413$; the average for those who categorized their positions as library science was $\$ 39,580$. Women who categorized their positions as information science earned an average starting salary of $\$ 46,118$; men averaged $\$ 55,423 .^{12}$ Salary statistics substantiate the research showing that information technology positions are more highly valued and therefore more highly compensated in the library organization. Likewise, men are more highly compensated than women.

One of the causes of income inequality is occupational 
segregation. ${ }^{13}$ Occupational segregation occurs when positions with similar educational requirements, but different titles or locations within the organization, are valued differently. ${ }^{14}$ The difference in the salaries of traditional library department heads and the heads of technology departments is one example of income inequality within the library. According to the ARL Annual Salary Survey 2007-08, heads of computer systems departments earn more than $\$ 87,100$ while heads of rare books and manuscripts departments, who have the second highest salaries, earn $\$ 80,628$. The rare books and manuscripts department heads are nearly evenly divided by gender; the majority of computer systems department heads are men. ${ }^{15}$

In libraries, occupational segregation divides traditional library departments and functions from IT departments and technology applications. Librarians are predominately female and, as the occupational statistics show, IT workers are predominately male. The result for libraries has been a gendered segregation of the library workforce. ${ }^{16}$

The results of occupational segregation are intensified by the tendency for women to avoid defining themselves as technology workers. The research by Adam et al. confirms the results of several earlier studies. When asked to define their roles in the organization, men more often associate their positions with IT; women tend to identify with a larger or more encompassing group within the organization, not specifically IT. ${ }^{17}$ Though these studies did not include librarians, it could be assumed that female librarians would respond much like their counterparts in other industries. In fact, few occupational studies conducted outside the library profession include librarians. Thus it appears that women choose to be excluded from an occupational group that is well compensated, integral to the organization, and considered highly skilled.

Not only do women define their positions as nonIT, but women also underestimate their technical skills. Hargittai and Shafer reviewed a number of studies investigating the self-assessment of computer skills. In those studies, women test at the same skill level as men but consistently underrate their technical ability. Hargittai and Shafer conducted a study of Internet skills that draws the same conclusion. ${ }^{18}$

\section{Organizational culture}

Women may underestimate their abilities and disassociate with IT in part because of the perception of IT organizational culture. ${ }^{19}$ Technical positions are associated with long and irregular hours, leading to the assumption that family and home responsibilities will cause women to be less able to contribute. As Ramsey and McCorduck note, those assumptions are not associated with men's work. ${ }^{20}$ They emphasize that while women "often shoulder more family responsibilities than men ... the presumption more than the reality tends to limit women's advancement."21

The perception of a high commitment level is fostered by the computing industries. The stereotype of the solitary computer geek, typing away in physical, though not virtual, isolation with a social life revolving around the technology is not entirely accurate. Yet Guzman, Stam, and Stanton have studied IT as an occupational subculture. They call the perceived demands of the subculture "extreme and unusual," with long hours and constant need for self reeducation. ${ }^{22}$ The appearance of high cost in time and capital is one way that the already-initiated keep outsiders out. The use of specialized language and jargon, stories of long hours spent, and complaints about end users are all means of solidifying organizational boundaries. The Ramsey and McCorduck report points to a perception by some women that the long hours are often "a status symbol, a sign of machismo." 23 All occupational groups participate in us-versus-them behavior however; since IT is gendered, the subculture effectively excludes women and exacerbates the segregation.

According to Guzman, Stam, and Stanton's research, one of the hallmarks of the IT subculture is the sense of control over other groups within the organization. Yet the subculture also shares a sense of fulfillment in assisting others with technology. ${ }^{24}$ The esoteric knowledge held by IT workers is essential to the operation of most organizations, in particular libraries. This gives the subculture an inordinate sense of power. ${ }^{25}$ The computing professions appear to be linked with masculinity and power, at least in Western cultures. Melanie Wilson writes, "The qualities required for entry to the professions and success in them are seen as masculine." ${ }^{26}$ Masculine occupations tend to be associated with skill, learning, and hard work. Construction, business, and now IT have a preponderance of male professionals. Masculine occupations are more prestigious and better compensated. Wacjman writes, "To be in command of the very latest technology signifies being involved in directing the future, so it is a highly valued and mythologized activity." 27 The idea that women's skills are more instinctive makes them less valued, and feminized occupations tend to be associated with the innate behaviors. ${ }^{28}$ Wilson points to research indicating that "women's work tends to be regarded as semi-skilled merely because it is women's work." 29 Women are a higher percentage of elementary school teachers, nurses, and care givers, and those positions receive modest compensation compared to occupations typically held by men. Specific to libraries, technology subfields may be seen as acceptable positions for men in an occupation traditionally dominated by women.

As the research suggests, an increase in the number of women involved in technology would devalue those fields. Roos and Reskin explored the effect of an increase 
in the numbers of women on occupational status. In a 1990 paper they wrote,

Traditionally, "women's" jobs have been both lowerpaying and less valued than "men's." Occupational incumbents have thus been chagrined to learn that their occupation is feminizing, fearful of a drop in wages and prestige. This fear has a valid empirical basis: the percentage female in an occupation is negatively correlated with occupational earnings. ${ }^{30}$

An influx of women into library IT would likely devalue the subfield and depress wages; as such, occupational segregation is one means of protecting wages and influence.

Women are often deterred from entering or excelling in an occupation through subtle discrimination. Because the sexist actions or words are not always recognized as discriminatory, subtle sexism is difficult to define. The repetition of the behaviors and language over time creates a sense that those patterns are acceptable, and they become more difficult to change. ${ }^{31}$ Examples of subtle sexism include the expectation that the women will be more responsible for social occasions involving food or more responsible for the staff lounge or lunch room. Often the informal exchange of information and skills, so-called boy's-room knowledge, eludes women because they are excluded from masculine socializing. In addition, men may be assigned different, usually less clerical tasks, and women are often associated with the softer tasks of user support, help desks and interfaces. ${ }^{32}$ Although subtle discrimination occurs in all work places, not just libraries, the effects in a gender-segregated workplace are compounded. Confronted with a complex series of social, cultural, and organizational cues, women are made to feel less competent and less comfortable with technology. The association of women's positions with lower wages and prestige serves to sustain the occupational segregation and justify the subtle discrimination that hinders women.

Sometimes perception creates reality. It would be a mistake to group all women as a whole, expecting that the experiences of all are exactly alike, just as not all men are technologically adept. Socioeconomic factors, as well as ethnic and geographic differences, influence the abilities and desires of women and men to succeed in technology professions. Yet the smaller number of women in technology subfields of librarianship implies an almost "symbolic image of the discipline as masculine, which in turn reinforces the minority position of women." 33 Likewise, the far greater number of women writing in children's librarianship simply reinforces this subfield as feminine. According to Alksnis, "On the demand side, jobs are often seen as requiring the characteristics of the group that already dominates it." 34 The lack of women in the IT field continues to reinforce the stereotype and perpetuate the imbalance.

\section{Conclusion}

To remedy the underrepresentation of women in IT, it would be simple to call for greater educational opportunities for girls, mentoring programs for young professional women, and economic incentives to retain mid-career women. The situation, however, is not simple. A series of organizational, societal, and cultural perceptions inhibit women from associating or identifying with IT. Rasmussen and Hapnes refer to a combination of organizational culture and gender politics that discourage women. ${ }^{35}$ Instead of a focus on the numbers of women in IT, librarians should work to transform the organizational culture. As technology progresses, the definition of technology work must be reevaluated and the entries into the technology fields must be redefined. In short, what constitutes IT must be rethought, recast, and revalued as technology develops. In the library specifically, IT and librarianship have much in common. At present, the library has a dichotomized workforce of female librarians and male IT workers. Over time, the skills of librarians and technologists will blend. If managed properly, the best of classic library theory and practice will combine with IT into a dynamic and diverse workforce as well as a thriving and innovative organization.

\section{References and notes}

1. Examples of research and statistics concerning the number and status of women in technology fields, in addition to those noted in the paper, include Carol Simard et al., Climbing the Technical Ladder: Obstacles and Solutions for Mid-Level Women in Technology (Palo Alto, Calif.: Anita Borg Institute for Women and Technology, 2008), http://anitaborg.org/files/Climbing_the Technical_Ladder.pdf (accessed Oct. 20, 2008); U.S. Department of Labor, Bureau of Labor Statistics, Household Data Annual Averages, "Table 11. Employed Persons by Detailed Occupation, Sex, Race and Hispanic or Latino Ethnicity," ftp://ftp.bls.gov/ pub/special.requests/lf/aat11.txt (accessed Oct. 20, 2008); and Jay Vesgo, "CRA Taulbee Trends: Female Students and Faculty," Computing Research Association, June 17, 2008, www.cra.org/ info/taulbee/women.html (accessed Oct. 20, 2008).

2. National Science Foundation, Division of Science Resources Statistics, Women, Minorities, and Persons with Disabilities in Science and Engineering: 2007, NSF 07-315, Table H-5, Employed Scientists and Engineers by Occupation, Highest Degree Level, and Sex: 2003 (Arlington, Va.: National Science Foundation, 2007): 222, http:/ / www.nsf.gov/statistics/wmpd/ pdf/nsf07315.pdf (accessed June 11, 2008).

3. National Science Foundation, Division of Science Resources Statistics, Women, Minorities, and Persons with Disabilities in Science and Engineering: 2007, Table H-16, Median Annual Salary of Scientists and Engineers Employed Full Time, by Highest Degree, Broad Occupation, Age Group, and Sex: 2003, 225.

4. Association of Research Libraries, ARL Annual Salary Survey 2007-08, Table 17, Number and Average Salaries by Position 
and Sex (Washington, D.C.: ARL, 2008): 42-43, tables 17-18 www.arl.org/stats/annualsurveys/salary/annualedssal.shtml (accessed Aug. 2008).

5. Sook Lim, "Job Satisfaction of Information Technology Workers in Academic Libraries," Library $\mathcal{E}$ Information Science Research 30, no. 2 (2008): 120.

6. Stephanie Maatta, "Placements and Salaries 2006: What's an MLIS Worth?" Library Journal (Oct. 15, 2007), www.library journal.com/article/CA6490671.html (accessed Aug. 29, 2008)

7. Malin Hakanson, "The Impact of Gender on Citations: An Analysis of College \& Research Libraries, Journal of Academic Librarianship and Library Quarterly," College E Research Libraries 66, no. 4 (2005): 312-22.

8. Bente Rasmussen and Tove Hapnes, "Excluding Women from the Technologies of the Future? A Case Study of the Culture of Computer Science," Futures 23, no. 10 (1991): 1107.

9. Krista Scott-Dixon, "From Digital Binary to Analog Continuum: Measuring Gendered IT Labor: Notes toward Multidimensional Methodologies," Frontiers 26, no. 1 (2005): 26.

10. Ibid.

11. Ibid., 30 .

12. Stephanie Maatta, "Placements and Salaries 2006."

13. Christine Alksnis, Serge Desmarais, and James Curtis, "Workforce Segregation and the Gender Wage Gap: Is Women's Work Valued as Highly as Men's?" Journal of Applied Social Psychology 38, no. 6 (2008): 1416-41.

14. Ibid., 1419.

15. Association of Research Libraries, ARL Annual Salary Survey 2007-08, 42-43, tables 17-18.

16. Lori Ricigliano and Renee Houston, "Men's Work, Women's Work: The Social Shaping of Technology in Academic Libraries," (paper presented at the Association of College and Research Libraries 11th Annual National Conference, Charlotte, N.C., Apr. 10-13, 2003): 1.

17. Alison Adam et al., "Being an 'It' in IT: Gendered Identities in IT," European Journal of Information Systems 15, no. 4 (2006): 368-78.

18. Eszter Hargittai and Steven Shafer, "Differences in Actual and Perceived Online Skills: The Role of Gender," Social Science Quarterly 87, no. 2 (2006): 432-48.

19. Rasmussen and Hapnes, "Excluding Women," 1108.
20. Nancy Ramsey and Pamela McCorduck, "Where are the Women in Information Technology? Preliminary Report of Liberature Search and Interviews" (report prepared for the National Center for Women and Information Technology, Feb. 5, 2005): 9, http://www.anitaborg.org/files/abi_wherearethe women.pdf (accessed June 12, 2009).

21. Ibid.

22. Indira R. Guzman, Kathryn R. Stam, and Jeffrey M. Stanton, "The Occupational Culture of IS/IT Personnel within Organizations," The DATA BASE for Advances in Information Systems 39, no. 1 (2008): 45.

23. Ramsey and McCorduck, "Where are the Women in Information Technology?" 9

24. Guzman, Stam, and Stanton, "Occupational Culture," 45.

25. Ibid.

26. Melanie Wilson, "A Conceptual Framework for Studying Gender in Information Systems Research," Journal of Information Technology 19, no. 1 (2004): 87.

27. Judy Wajcman, "Reflections on Gender and Technology Studies: What is State of the Art?" Social Studies of Science 30, no. 3 (June 2000): 454.

28. Alksnis, Desmarais, and Curtis, "Workforce Segregation," 1418.

29. Wilson, "Conceptual Framework," 85.

30. Patricia A. Roos and Barbara F. Reskin, "Occupational Desegregation in the 1970s: Integration and Economic Equality?" Sociological Perspectives 35, no.1 (1992): 87.

31. Nijole V. Benokraitis, "Sex Discrimination in the 21st Century," in Subtle Sexism: Current Practice and Prospects for Change, ed. Nijole V. Benokraitis (Thousand Oaks, Calif.: Sage, 1997): 11.

32. Fiona Wilson, "Can Compute, Won't Compute: Women's Participation in the Culture of Computing," New Technology, Work and Employment 18, no. 2 (2003): 127.

33. Vivian Anette Lagesen, "Extreme Make-over? The Making of Gender and Computer Science" (PhD diss., Norwegian University of Science and Technology, Trondheim, Norway, 2005): 188.

34. Alksnis, Desmarais, and Curtis, "Workforce Segregation," 1419.

35. Rasmussen and Hapnes, "Excluding Women," 1108. 